\title{
Value of HCV Core Antigen Testing in Detection of HCV Antibody Negative HCV Infection in Patients with Asymptomatic Elevation of Liver Transaminases of Unknown Etiology
}

\author{
Ibrahim M. Ibrahim ${ }^{1}$, Mohammed H. Murad ${ }^{2}$ \\ ${ }^{1}$ Tropical Medicine Department, Faculty of Medicine, Zagazig University, Egypt \\ ${ }^{2}$ Clinical Pathology Department, Faculty of Medicine, Zagazig University, Egypt
}

Corresponding Author Ibrahim M. Ibrahim

Mobile: 01225771945

E mail:

Ibrahimibrahim1979@ yahoo.com

Key words:

HCV antibody

negative, $H C V$ core antigen, HCV RNA $P C R$ and elevation of liver enzymes of unknown etiology
Background and aim of the work: Elevation of liver transaminases is the marker of hepatocyte affection by an inflammatory process. $\mathrm{HCV}$ infection is a common infection in Egypt. HCV antibodies are detected at least 6 weeks from the onset of infection; a period of time which is called window or preseroconversion phase. Moreover, the immune system is so weak as to mount for a detectable level of HCV antibodies as in cases of HIV, lymphomas and patients on chemotherapy. The aim of the present work is to study $\mathrm{HCV}$ core antigen as a marker of $\mathrm{HCV}$ infection in $\mathrm{HCV}$ antibody negative patients with asymptomatic elevation of liver transaminases of unknown etiology.

Patients and Methods: 110 asymptomatic patients with elevated liver transaminases of unknown etiology were included in the study; 55 of them were HCV antibody negative and 55 were $\mathrm{HCV}$ antibody positive. HCV core antigen and HCV RNA PCR were determined in all patients. HCV antibody testing was repeated in all HCV antibody negative patients after 6 weeks.

Results: Out of $55 \mathrm{HCV}$ antibody negative patients with elevated liver transaminases of unknown etiology, 5 turned out to have $\mathrm{HCV}$ infection as proved by HCV RNA PCR. 4 of these 5 were positive for $\mathrm{HCV}$ core antigen. 3 of these 5 converted to $\mathrm{HCV}$ antibody positive after 6 weeks of follow up.

Conclusion: HCV core antigen is a good marker for detection of $\mathrm{HCV}$ infection in HCV antibody negative patients with asymptomatic elevation of liver transaminases of unknown etiology.

drug history of an essentially or a INTRODUCTION

Liver transaminases are the biochemical markers of hepatocyte affection by an inflammatory process. Accidental discovery of isolated elevation of liver transaminases in asymptomatic patients is not uncommonly met with in the daily practice in the setting of routine or periodic self-health screening, routine follow up of workers in hospitals and some factories or in the setting of routine preoperative, pre-blood donation and pre-traveling evaluation [1].

Elevation of liver transaminases of unknown etiology is defined as elevation of ALT and/or AST in a non-alcoholic patient in the absence of positive viral markers (HBs antigen and HCV antibody), absence of immune markers (ANA), absence of potentially hepatotoxic medication, absence of clinical and sonographic criteria of fatty liver disease and absence of family history of liver disease [2].

In the life cycle of $\mathrm{HCV}$, acute hepatitis $\mathrm{C}$ is defined as the first 2 months of $\mathrm{HCV}$ infection. In this period of time, the patient is mostly asymptomatic or may complain of non-specific abdominal discomfort or non-specific fatigue. Also in this period of time, liver enzymes may or may not become elevated [3].

Prevalence of HCV infection is variable throughout the world. In the USA, 1.8 percent of the population is positive for $\mathrm{HCV}$ antibodies. Given that 3 of every 4 seropositive persons also have viremia as assessed by the 
currently available HCV RNA PCR tests, an estimated 2.7 million people in the USA have active HCV infection [4].

Egypt possibly carries the highest $\mathrm{HCV}$ prevalence worldwide with approximately $30-35 \%$ of the general population infected [5]. HCV is considered the most common etiology of chronic liver disease in Egypt where prevalence of antibodies to $\mathrm{HCV}$ is 10 folds that in the USA and Europe. Approximately $90 \%$ of Egyptian HCV isolates belong to genotype $4 \mathrm{a}$ [6].

Early published results that identified HCV viral antigen in the serum of $\mathrm{HCV}$ infected patients were reported in 1992. One pioneering study indicated that circulating $\mathrm{HCV}$ core antigen could be detected through an enzyme-linked immunosorbent assay (ELISA) sandwich antigen test [7]. In 1995, it was demonstrated that HCV core antigen could be detected and quantified in serum through a simple fluorescent enzyme immunoassay. This procedure required a precipitation step followed by solubilization of the pellet both to reveal the HCV core antigen and to destroy antibodies that may prevent detection of $\mathrm{HCV}$ core protein. The processed sample could then be tested for $\mathrm{HCV}$ core antigen [8].

There have been multiple studies indicating the potential utility of $\mathrm{HCV}$ core antigen testing in three different types of situations; first, to identify $\mathrm{HCV}$ infection in the pre-seroconversion window period [9], second, to distinguish actively infected $\mathrm{HCV}$ seropositive individuals from those who have resolved HCV infection [10] and third, to monitor the efficacy of antiviral therapy using a quantitative HCV core antigen assay [11].

The aim of the present study is to evaluate the clinical utility of $\mathrm{HCV}$ core antigen testing in detection of $\mathrm{HCV}$ antibody negative $\mathrm{HCV}$ infection in patients with asymptomatic elevation of liver transaminases of unknown etiology.

\section{PATIENTS AND METHODS}

This study was carried out on 110 asymptomatic patients with elevated liver transaminases. Patients were recruited from the outpatient clinic of Tropical Medicine Department, Zagazig University Hospitals and the HCV treatment center at Al Ahrar hospital in the period from April 2015 to February 2017.
Patients with elevated liver transaminases were divided into two groups; group A which included 55 patients with negative HCV antibody and no identifiable cause of liver transaminase elevation and group B which included 55 patients with positive HCV antibody. Group A patients were recruited from the outpatient clinic of Tropical Medicine Department, Zagazig University hospitals. They accidentally discovered liver transaminase elevation in the setting of routine or periodic self-health screening, routine follow up of workers in hospitals and some factories or in the setting of routine preoperative, pre-blood donation and pre-traveling evaluation. Group B patients were recruited from $\mathrm{Al}$ Ahrar $\mathrm{HCV}$ treatment center.

HBs antigen positivity, alcoholism, hepatotoxic drug use, ANA positivity, BMI more than 35, sonographically bright fatty liver and hepatocellular carcinoma excluded patients from both groups. Sonographically cirrhotic liver did not exclude patients from either groups. All patients gave a written consent to be included in the study.

All patients were subjected to full history taking and thorough clinical examination. Routine laboratory investigations in the form of $\mathrm{CBC}$ and LFT were done for all patients. HBs antigen and ANA were done for all patients ascertain negativity in all patients. HCV antibody by ELISA, HCV core antigen by a prototype ELISA and quantitative HCV RNA PCR were done for all patients. HCV antibody testing was repeated after 6 weeks for HCV infected patients who are initially $\mathrm{HCV}$ antibody negative prior to receiving antiviral treatment. Pelviabdominal ultrasound was done for all patients by the same operator.

$\mathrm{HCV}$ core antigen detection was performed using a prototype ELISA. This sandwich assay utilizes microwells coated with monoclonal antibodies which recognize $\mathrm{HCV}$ core antigen. The conjugate comprised of anti-HCV core antigen monoclonal antibodies labeled with horseradish peroxidase and had different epitope specificity than the antibodies coated onto the solid phase [12].

Obtained data were collected, tabulated and statistically analyzed using SPSS 22.0 for windows (SPSS Inc., Chicago, IL, USA) and MedCalc 13 for windows (MedCalc Software bvba, Ostend, Belgium). Continuous quantitative variables were expressed as the mean \pm SD and median (range) and categorical qualitative variables were expressed as an absolute frequency (number) and a relative frequency (percentage). Continuous 
data were checked for normality using Shapiro Walk test. Independent samples Student's t-test was used to compare two groups of normally distributed data while Mann-Whitney U test was used for non-normally distributed data. Categorical data were compared using Chi-square test or
Fisher's exact test when appropriate. All tests were two sided. P-value $<0.05$ was considered statistically significant $(\mathrm{S}), \mathrm{p}$-value $<0.001$ was considered statistically highly significant (HS) and $p$-value $\geq 0.05$ was considered statistically non-significant (NS).

\section{RESULTS}

Table (1): Demographic data of the studied patients

\begin{tabular}{|c|c|c|c|c|c|c|}
\hline \multirow{2}{*}{ Demographic data } & \multicolumn{2}{|c|}{ Negative HCV Ab } & \multicolumn{2}{|c|}{ Positive HCV Ab } & \multirow{2}{*}{ Test } & \multirow{2}{*}{$\begin{array}{l}\text { p-value } \\
\text { (Sig.) }\end{array}$} \\
\hline & No. & $\%$ & No. & $\%$ & & \\
\hline \multicolumn{7}{|l|}{$\underline{\text { Sex }}$} \\
\hline Male & 39 & $70.9 \%$ & 36 & $65.5 \%$ & \multirow[t]{2}{*}{$0.377 \ddagger$} & \multirow{2}{*}{$\begin{array}{c}0.539(\mathrm{NS}) \\
(\mathrm{NS})\end{array}$} \\
\hline Female & 16 & $29.1 \%$ & 19 & $34.5 \%$ & & \\
\hline \multicolumn{7}{|l|}{ Age (years) } \\
\hline Mean \pm SD & \multicolumn{2}{|c|}{$41.56 \pm 12.96$} & \multicolumn{2}{|c|}{$42.25 \pm 12.91$} & \multirow[t]{2}{*}{$-0.280 *$} & \multirow{2}{*}{$\begin{array}{c}0.780(\mathrm{NS}) \\
(\mathrm{NS})\end{array}$} \\
\hline Median (Range) & \multicolumn{2}{|c|}{$44(19-71)$} & \multicolumn{2}{|c|}{$44(19-73)$} & & \\
\hline$\leq 40$ years & 26 & $47.3 \%$ & 25 & $45.5 \%$ & \multirow[t]{3}{*}{$0.040 \ddagger$} & \multirow[t]{3}{*}{$0.980(\mathrm{NS})$} \\
\hline $41-59$ years & 24 & $43.6 \%$ & 25 & $45.5 \%$ & & \\
\hline$\geq 60$ years & 5 & $9.1 \%$ & 5 & $9.1 \%$ & & \\
\hline \multicolumn{7}{|l|}{ Weight (kg) } \\
\hline Mean \pm SD & \multicolumn{2}{|c|}{$76.43 \pm 10.12$} & \multicolumn{2}{|c|}{$77.10 \pm 10.26$} & \multirow[t]{2}{*}{$-0.413 \bullet$} & \multirow{2}{*}{$\begin{array}{c}0.679(\mathrm{NS}) \\
(\mathrm{NS})\end{array}$} \\
\hline Median (Range) & \multicolumn{2}{|c|}{$77(55-91)$} & \multicolumn{2}{|c|}{$78(57-91)$} & & \\
\hline \multicolumn{7}{|l|}{ Height $(\mathrm{cm})$} \\
\hline Mean \pm SD & \multicolumn{2}{|c|}{$171.72 \pm 8$} & \multicolumn{2}{|c|}{$172.47 \pm 8.41$} & \multirow[t]{2}{*}{$-0.476^{*}$} & \multirow{2}{*}{$\begin{array}{c}0.635(\mathrm{NS}) \\
\text { (NS) }\end{array}$} \\
\hline Median (Range) & \multicolumn{2}{|c|}{$172(155-186)$} & \multicolumn{2}{|c|}{$172(155-186)$} & & \\
\hline \multicolumn{7}{|l|}{ BMI $\left(\mathrm{kg} / \mathrm{m}^{2}\right)$} \\
\hline Mean \pm SD & \multicolumn{2}{|c|}{$25.80 \pm 1.79$} & \multicolumn{2}{|c|}{$25.79 \pm 1.64$} & \multirow[t]{2}{*}{$-0.021 \bullet$} & $0.983(\mathrm{NS})$ \\
\hline Median & & & & & & \\
\hline Normal & 18 & $32.7 \%$ & 19 & $34.5 \%$ & $0.041 \dagger$ & $0.840(\mathrm{NS})$ \\
\hline Overweight & 37 & $67.3 \%$ & 36 & $65.5 \%$ & & $(\mathrm{NS})$ \\
\hline
\end{tabular}

\$ Chi-square test. * Independent samples Student's t-test. • Mann Whitney U test.

$\mathrm{P}<0.05$ is significant.

Table (2): Liver enzymes of the studied patients

\begin{tabular}{|c|c|c|c|c|c|c|}
\hline \multirow{2}{*}{ Liver enzymes } & \multicolumn{2}{|c|}{ Group A } & \multicolumn{2}{|c|}{ Group B } & \multirow{2}{*}{ Test } & \multirow{2}{*}{$\begin{array}{c}\text { p-value } \\
\text { (Sig.) }\end{array}$} \\
\hline & No. & $\%$ & No. & $\%$ & & \\
\hline \multicolumn{7}{|l|}{$\operatorname{AST}(\mathrm{U} / \mathrm{L})$} \\
\hline Mean \pm SD & \multicolumn{2}{|c|}{$163.20 \pm 51.51$} & \multicolumn{2}{|c|}{$192.72 \pm 93.52$} & \multirow{2}{*}{$-1.639 \bullet$} & \multirow{2}{*}{$\begin{array}{c}0.101(\mathrm{NS}) \\
(\mathrm{NS})\end{array}$} \\
\hline Median (Range) & \multicolumn{2}{|c|}{$143(123-410)$} & \multicolumn{2}{|c|}{$153(123-513)$} & & \\
\hline 3-10 time normal & 54 & $98.2 \%$ & 50 & $90.9 \%$ & \multirow{2}{*}{$2.821 \%$} & \multirow{2}{*}{$\begin{array}{c}0.206(\mathrm{NS}) \\
(\mathrm{NS})\end{array}$} \\
\hline$>10$ time normal & 1 & $1.8 \%$ & 5 & $9.1 \%$ & & \\
\hline \multicolumn{7}{|l|}{$\underline{\operatorname{ALT}(\mathbf{U} / \mathbf{L})}$} \\
\hline Mean \pm SD & \multicolumn{2}{|c|}{$189.60 \pm 77.66$} & \multicolumn{2}{|c|}{$208.90 \pm 97.62$} & \multirow{2}{*}{$-1.063 \bullet$} & \multirow{2}{*}{$\begin{array}{c}0.288(\mathrm{NS}) \\
(\mathrm{NS})\end{array}$} \\
\hline Median (Range) & \multicolumn{2}{|c|}{$174(123-515)$} & \multicolumn{2}{|c|}{$178(123-518)$} & & \\
\hline 3-10 time normal & 52 & $94.5 \%$ & 49 & $89.1 \%$ & \multirow{2}{*}{$1.089 \$$} & \multirow{2}{*}{$\begin{array}{c}0.489(\mathrm{NS}) \\
(\mathrm{NS})\end{array}$} \\
\hline$>10$ time normal & 3 & $5.5 \%$ & 6 & $10.9 \%$ & & \\
\hline
\end{tabular}

- Mann Whitney U test. $\quad$ † Chi-square test. $\mathrm{P}<0.05$ is significant. 
Table (3): Routine laboratory findings of the studied patients

\begin{tabular}{|c|c|c|c|c|}
\hline $\begin{array}{c}\text { Routine laboratory } \\
\text { Findings }\end{array}$ & $\begin{array}{c}\text { Group A } \\
(\mathrm{N}=55)\end{array}$ & $\begin{array}{c}\text { Group B } \\
(\mathrm{N}=55)\end{array}$ & Test• & p-value 9 (Sig.) \\
\hline \multicolumn{5}{|l|}{ AST (IU/dl) } \\
\hline Mean \pm SD & $163.20 \pm 51.51$ & $192.72 \pm 93.52$ & -1.639 & 0.101 \\
\hline Median (Range) & $143(123-410)$ & $153(123-513)$ & & $(\mathrm{NS})$ \\
\hline \multicolumn{5}{|l|}{ ALT (IU/dl) } \\
\hline Mean \pm SD & $189.60 \pm 77.66$ & $208.90 \pm 97.62$ & -1.063 & 0.288 \\
\hline Median (Range) & $174(123-515)$ & $178(123-518)$ & & $(\mathrm{NS})$ \\
\hline \multicolumn{5}{|l|}{ T.Bil (mg/dl) } \\
\hline Mean \pm SD & $1.14 \pm 0.61$ & $1.43 \pm 0.94$ & -1.725 & 0.085 \\
\hline Median (Range) & $1(0.50-4)$ & $1.10(0.40-5.10)$ & & $(\mathrm{NS})$ \\
\hline \multicolumn{5}{|l|}{ Albumin (g/dl) } \\
\hline Mean \pm SD & $3.98 \pm 0.49$ & $3.85 \pm 0.37$ & -0.934 & 0.350 \\
\hline Median (Range) & $3.90(3.40-5)$ & $3.80(3.30-5)$ & & $(\mathrm{NS})$ \\
\hline \multicolumn{5}{|l|}{ INR } \\
\hline Mean \pm SD & $1.04 \pm 0.12$ & $1.08 \pm 0.14$ & -2.228 & 0.026 \\
\hline Median (Range) & $1(0.98-1.50)$ & $1(1-1.60)$ & & $(\mathrm{S})$ \\
\hline \multicolumn{5}{|l|}{ WBCs $\left(x 10^{3} / \mathrm{mm}^{3}\right)$} \\
\hline Mean \pm SD & $7.10 \pm 2.31$ & $7.17 \pm 3.23$ & -0.803 & 0.422 \\
\hline Median (Range) & $7(4-17)$ & $7(3-18)$ & & (NS) \\
\hline \multicolumn{5}{|l|}{ Hemoglobin (g/dl) } \\
\hline Mean \pm SD & $12.31 \pm 1.48$ & $11.40 \pm 0.92$ & -3.820 & $<0.001$ \\
\hline Median (Range) & $12(9.80-17)$ & $11(9.90-15)$ & & $(\mathrm{HS})$ \\
\hline \multicolumn{5}{|l|}{ PIt count $\left(\mathrm{x}^{3} 0^{3} / \mathrm{mm}^{3}\right)$} \\
\hline Mean \pm SD & $186.94 \pm 42.02$ & $147.12 \pm 60.61$ & -3.656 & $<0.001$ \\
\hline Median (Range) & $178(100-321)$ & $148(45-300)$ & & $\overline{(\mathrm{HS})}$ \\
\hline
\end{tabular}

- Mann Whitney U test. $\quad \mathrm{P}<0.05$ is significant.

Table (4): Liver ultrasonography of the studied patients

\begin{tabular}{|l|c|c|c|c|c|c|}
\hline \multirow{2}{*}{ Liver U/S } & \multicolumn{2}{|c|}{ Group A (N=55) } & \multicolumn{2}{|c|}{ Group B (N=55) } & \multirow{2}{*}{ Test +} & \multirow{2}{*}{ p-value (Sig.) } \\
\cline { 2 - 5 } & No. & \% & No. & \% & & \\
\hline Normal & 55 & $100 \%$ & 31 & $56.4 \%$ & 30.698 & $<0.001(\mathrm{HS})$ \\
\hline Cirrhotic & 0 & $0 \%$ & 24 & $43.6 \%$ & & \\
\hline Chi-square test.
\end{tabular}

Table (5): Distribution of HCV antibody, HCV core antigen and HCV RNA PCR among the studied patients

\begin{tabular}{|c|c|c|c|c|}
\hline \multirow{2}{*}{ HCV Ab } & \multirow{2}{*}{ HCV core Ag } & \multirow{2}{*}{ HCV PCR } & \multicolumn{2}{|c|}{ All patients (N=110) } \\
\cline { 4 - 5 } & & & No. & \% \\
\hline$+\mathrm{ve}$ & $+\mathrm{ve}$ & $+\mathrm{ve}$ & 44 & $40 \%$ \\
\hline$+\mathrm{ve}$ & $+\mathrm{ve}$ & $-\mathrm{ve}$ & 0 & $0 \%$ \\
\hline$+\mathrm{ve}$ & $-\mathrm{ve}$ & $+\mathrm{ve}$ & 3 & $2.7 \%$ \\
\hline$+\mathrm{ve}$ & $-\mathrm{ve}$ & $-\mathrm{e}$ & 8 & $7.3 \%$ \\
\hline$-\mathrm{ve}$ & $+\mathrm{ve}$ & $+\mathrm{ve}$ & 4 & $3.6 \%$ \\
\hline$-\mathrm{ve}$ & $+\mathrm{ve}$ & $-\mathrm{ve}$ & 0 & $0 \%$ \\
\hline$-\mathrm{ve}$ & $-\mathrm{ve}$ & $+\mathrm{ve}$ & 1 & $0.9 \%$ \\
\hline$-\mathrm{ve}$ & $-\mathrm{ve}$ & $-\mathrm{ve}$ & 50 & $45.5 \%$ \\
\hline
\end{tabular}


Table (6): HCV seromarkers of the studied patients

\begin{tabular}{|l|c|c|c|c|c|c|}
\hline \multirow{2}{*}{ HCV seromarker } & \multicolumn{2}{|c|}{ Group A (N=55) } & \multicolumn{2}{c|}{ Group B (N=55) } & \multirow{2}{*}{ Test: } & \multirow{2}{*}{ p-value } \\
\cline { 2 - 5 } & No. & $\mathbf{\%}$ & No. & \% & & \\
\hline HCV Ab & & & & & & \\
\hline Negative & 55 & $100 \%$ & 0 & $0 \%$ & 110.000 & $<0.001$ \\
\hline Positive & 0 & $0 \%$ & 55 & $100 \%$ & & $(\mathrm{HS})$ \\
\hline HCV core Ag & & & & & & \\
\hline Negative & 51 & $92.7 \%$ & 11 & $20 \%$ & 59.140 & $<0.001$ \\
\hline Positive & 4 & $7.3 \%$ & 44 & $80 \%$ & & $(\mathrm{HS})$ \\
\hline
\end{tabular}

$\$$ Chi-square test. $\quad \mathrm{P}<0.05$ is significant.

Table (7): HCV RNA PCR of the studied patients

\begin{tabular}{|l|c|c|c|c|c|c|}
\hline \multirow{2}{*}{ HCV RNA levels by PCR } & \multicolumn{2}{|c|}{ Group A (N=) } & \multicolumn{2}{|c|}{ Group B (N=) } & \multirow{2}{*}{ Test $\$$} & \multirow{2}{*}{ p-value } \\
\cline { 2 - 5 } & No. & $\%$ & No. & $\%$ & & \\
\hline$<16 \mathrm{IU} / \mathrm{ml}$ & 50 & $90.9 \%$ & 8 & $14.5 \%$ & 64.720 & $<0.001$ \\
\hline $16-<10^{4} \mathrm{IU} / \mathrm{ml}$ & 2 & $3.6 \%$ & 19 & $34.5 \%$ & & $(\mathrm{HS})$ \\
\hline$>10^{4}-<10^{6} \mathrm{IU} / \mathrm{ml}$ & 1 & $1.8 \%$ & 18 & $32.7 \%$ & & \\
\hline$>10^{6} \mathrm{IU} / \mathrm{ml}$ & 2 & $3.6 \%$ & 10 & $18.2 \%$ & & \\
\hline
\end{tabular}

$<16 \mathrm{IU} / \mathrm{ml}$ (below level of detection) $\$$ Chi-square test $\quad \mathrm{P}<0.05$ is significant.

Table (8): Relation between HCV core antigen and HCV RNA PCR in HCV antibody negative patients

\begin{tabular}{|c|c|c|c|c|c|c|}
\hline \multirow{3}{*}{ HCV PCR } & \multicolumn{4}{|c|}{ Negative HCV Ab (group A) $(\mathbf{N}=55)$} & \multirow{3}{*}{ Test } & \multirow{3}{*}{$\begin{array}{l}\text { p-value } \\
\text { (Sig.) }\end{array}$} \\
\hline & \multicolumn{2}{|c|}{$\begin{array}{l}\text { Negative HCV core } A g \\
\qquad(N=51)\end{array}$} & \multicolumn{2}{|c|}{$\begin{array}{l}\text { Positive HCV core Ag } \\
\qquad(N=4)\end{array}$} & & \\
\hline & No. & $\%$ & No. & $\%$ & & \\
\hline Negative & 50 & $98 \%$ & 0 & $0 \%$ & \multirow{2}{*}{$43.137 \div$} & \multirow{2}{*}{$\begin{array}{c}<0.001(\mathrm{HS}) \\
(\mathrm{HS})\end{array}$} \\
\hline Positive & 1 & $2 \%$ & 4 & $100 \%$ & & \\
\hline$<16 \mathrm{IU} / \mathrm{ML}$ & 50 & $98 \%$ & 0 & $0 \%$ & \multirow{4}{*}{$47.586 \div$} & \multirow{4}{*}{$\begin{array}{c}<0.001 \\
(\mathrm{HS})\end{array}$} \\
\hline $16-10^{4} \mathrm{IU} / \mathrm{ML}$ & 1 & $2 \%$ & 1 & $25 \%$ & & \\
\hline $10^{4}-10^{6} \mathrm{IU} / \mathrm{ML}$ & 0 & $0 \%$ & 1 & $25 \%$ & & \\
\hline$>10^{6} \mathrm{IU} / \mathrm{ML}$ & 0 & $0 \%$ & 2 & $50 \%$ & & \\
\hline
\end{tabular}

$<16 \mathrm{IU} / \mathrm{ml}$ (below level of detection) $\quad \$$ Chi-square test $\quad \mathrm{P}<0.05$ is significant

Table (9): Relation between HCV core antigen and HCV RNA PCR in HCV antibody positive patients

\begin{tabular}{|c|c|c|c|c|c|c|}
\hline \multirow{3}{*}{ HCV PCR } & \multicolumn{4}{|c|}{ Positive HCV Ab (group B) (N=55) } & \multirow{3}{*}{ Test } & \multirow{3}{*}{$\begin{array}{l}\text { p-value } \\
\text { (Sig.) }\end{array}$} \\
\hline & \multicolumn{2}{|c|}{$\begin{array}{c}\text { Negative HCV core Ag } \\
(\mathrm{N}=11)\end{array}$} & \multicolumn{2}{|c|}{$\begin{array}{c}\text { Positive } \mathrm{HCV} \text { core } \mathrm{Ag} \\
(\mathrm{N}=\mathbf{4 4})\end{array}$} & & \\
\hline & No. & $\%$ & No. & $\%$ & & \\
\hline Negative & 8 & $72.7 \%$ & 0 & $0 \%$ & \multirow{2}{*}{$37.447 t$} & \multirow{2}{*}{$\begin{array}{c}<0.001(\mathrm{HS}) \\
(\mathrm{HS})\end{array}$} \\
\hline Positive & 3 & $27.3 \%$ & 44 & $100 \%$ & & \\
\hline$<16 \mathrm{IU} / \mathrm{ML}$ & 8 & $72.7 \%$ & 0 & $0 \%$ & \multirow{4}{*}{$37.913+$} & \multirow{4}{*}{$\begin{array}{c}<0.001 \\
(\mathrm{HS})\end{array}$} \\
\hline $16-10^{4} \mathrm{IU} / \mathrm{ML}$ & 2 & $18.2 \%$ & 17 & $38.6 \%$ & & \\
\hline $10^{4}-10^{6} \mathrm{IU} / \mathrm{ML}$ & 1 & $9.1 \%$ & 17 & $38.6 \%$ & & \\
\hline$>10^{6} \mathrm{IU} / \mathrm{ML}$ & 0 & $0 \%$ & 10 & $22.7 \%$ & & \\
\hline
\end{tabular}

$<16 \mathrm{IU} / \mathrm{ml}$ (below level of detection) $\$$ Chi-square test $\mathrm{P}<0.05$ is significant. 
Table (10): Liver enzymes among HCV core antigen negative and positive patients

\begin{tabular}{|c|c|c|c|c|}
\hline \multirow{2}{*}{$\begin{array}{c}\text { Routine laboratory } \\
\text { Findings }\end{array}$} & \multicolumn{2}{|c|}{ HCV core Ag } & \multirow[b]{2}{*}{ Test• } & \multirow[b]{2}{*}{ p-value } \\
\hline & $\begin{array}{c}\text { Negative }(\mathrm{N}=62) \\
(\mathrm{N}=62)\end{array}$ & $\begin{array}{c}\text { Positive }(\mathrm{N}=48) \\
(\mathrm{N}=48)\end{array}$ & & \\
\hline \multicolumn{5}{|l|}{ AST (IU/dl) } \\
\hline Mean \pm SD & $171.25 \pm 65.20$ & $186.62 \pm 89.18$ & -0.275 & 0.130 \\
\hline Median (Range) & $153(111-478)$ & $146.50(97-491)$ & & $(\mathrm{NS})$ \\
\hline \multicolumn{5}{|l|}{ ALT (IU/dl) } \\
\hline Mean \pm SD & $197.77 \pm 88.40$ & $201.16 \pm 89.14$ & -0.130 & 0.897 \\
\hline Median (Range) & $178(123-518)$ & $174(123-440)$ & & $(\mathrm{NS})$ \\
\hline
\end{tabular}

- Mann Whitney U test. $\mathrm{P}<0.05$ is significant.

Table (11): HCV antibody and HCV RNA PCR among HCV core antigen negative and positive patients

\begin{tabular}{|l|c|c|c|c|}
\hline \multirow{2}{*}{} & \multicolumn{3}{|c|}{ HCV core Ag } \\
\cline { 2 - 5 } & \multicolumn{2}{|c|}{ Negative (N=62) } & \multicolumn{2}{c|}{ Positive (N=48) } \\
\cline { 2 - 5 } & No. & \% & No. & \% \\
\hline $\mathrm{HCV} \mathrm{ab}+\mathrm{ve}$ & 51 & $82.3 \%$ & 4 & $8.3 \%$ \\
\hline $\mathrm{HCV} \mathrm{ab}-\mathrm{ve}$ & 11 & $17.7 \%$ & 0 & $91.7 \%$ \\
\hline$<16 \mathrm{IU} / \mathrm{ml}$ & 58 & $93.5 \%$ & 18 & $37.5 \%$ \\
\hline $16<10^{4} \mathrm{IU} / \mathrm{ml}$ & 3 & $4.8 \%$ & 18 & $37.5 \%$ \\
\hline$>10^{4}-<10^{6} \mathrm{IU} / \mathrm{ml}$ & 1 & $1.6 \%$ & 12 & $25 \%$ \\
\hline$>10^{6} \mathrm{IU} / \mathrm{ml}$ & 0 & $0 \%$ & & 0 \\
\hline
\end{tabular}

$<16 \mathrm{IU} / \mathrm{ml}$ (below level of detection).

Table (12): HCV RNA PCR among HCV core antigen negative and positive patients

\begin{tabular}{|c|c|c|c|c|c|c|}
\hline \multirow{3}{*}{$\begin{array}{c}\text { HCV RNA levels by } \\
\text { PCR }\end{array}$} & \multicolumn{4}{|c|}{ HCV core Ag } & \multirow{3}{*}{ Test $\ddagger$} & \multirow{3}{*}{ p-value } \\
\hline & \multicolumn{2}{|c|}{ Negative $(\mathrm{N}=62)$} & \multicolumn{2}{|c|}{ Positive $(\mathrm{N}=48)$} & & \\
\hline & No. & $\%$ & No. & $\%$ & & \\
\hline$<16 \mathrm{IU} / \mathrm{ml}$ & 58 & $93.5 \%$ & 0 & $0 \%$ & 95.693 & $<0.001$ \\
\hline $16<10^{4} \mathrm{IU} / \mathrm{ml}$ & 3 & $4.8 \%$ & 18 & $37.5 \%$ & & $\overline{(\mathrm{HS})}$ \\
\hline$>10^{4}-<10^{6} \mathrm{IU} / \mathrm{ml}$ & 1 & $1.6 \%$ & 18 & $37.5 \%$ & & \\
\hline$>10^{6} \mathrm{IU} / \mathrm{ml}$ & 0 & $0 \%$ & 12 & $25 \%$ & & \\
\hline
\end{tabular}

$<16 \mathrm{IU} / \mathrm{ml}$ (below level of detection) $\quad+$ Chi-square test $\mathrm{P}<0.05$ is significant.

Table (13): Relation between HCV core Ag and HCV antibody after 6 weeks in patients with initial negative HCV antibody

\begin{tabular}{|l|c|c|c|c|c|c|}
\hline $\begin{array}{c}\text { HCV Ab after } \\
6\end{array}$ & \multicolumn{2}{|c|}{$\begin{array}{c}\text { Negative HCV core Ag } \\
\text { (N=51) }\end{array}$} & \multicolumn{2}{|c|}{$\begin{array}{c}\text { Positive HCV core Ag } \\
\text { (N=4) }\end{array}$} & \multirow{2}{*}{ Test* } & $\begin{array}{c}\text { p-value } \\
\text { (Sig.) }\end{array}$ \\
\cline { 2 - 5 } & No. & $\mathbf{\%}$ & No. & \% & & \\
\hline Negative & 51 & $100 \%$ & 1 & $25 \%$ & 40.457 & $\begin{array}{c}<0.001 \text { (HS) } \\
\text { (HS) }\end{array}$ \\
\hline Positive & 0 & $0 \%$ & 3 & $75 \%$ & & \\
\hline
\end{tabular}

+ Chi-square test. $\quad \mathrm{P}<0.05$ is significant. 
Table (14): Relation between HCV RNA PCR and HCV antibody after 6 weeks in patients with initial negative HCV antibody

\begin{tabular}{|l|c|c|c|c|c|c|}
\hline \multirow{2}{*}{$\begin{array}{c}\text { HCV Ab after 6 } \\
\text { weeks }\end{array}$} & $\begin{array}{c}\text { Negative HCV PCR } \\
\text { (N=50) }\end{array}$ & \multicolumn{2}{|c|}{$\begin{array}{c}\text { Positive HCV PCR } \\
\text { (N=5) }\end{array}$} & \multirow{2}{*}{ Test $*$} & \multirow{2}{*}{$\begin{array}{c}\text { p-value } \\
\text { (Sig.) }\end{array}$} \\
\cline { 2 - 5 } & No. & \% & No. & $\%$ & & \\
\hline Negative & 50 & $100 \%$ & 2 & $40 \%$ & 31.731 & $\begin{array}{c}<0.001(\mathrm{HS}) \\
\text { (HS) }\end{array}$ \\
\hline Positive & 0 & $0 \%$ & 3 & $60 \%$ & & \\
\hline
\end{tabular}

$\ddagger$ Chi-square test. $\quad \mathrm{P}<0.05$ is significant

\section{DISCUSSION}

$\mathrm{HCV}$ infection is a commonly spreading infection in Egypt. The acute first-2-month phase of infection is mostly asymptomatic. Liver transaminases may or may not become elevated. Typically, the increase in liver tranaminases follows the presence of a detectable HCV RNA levels by about 1 to 2 weeks but generally precedes the development of HCV antibodies. The mean ALT after acute infection reaches $800 \mathrm{IU} / \mathrm{L}$ range. The Centers for Disease Control and Prevention uses a recent increase in ALT to a level greater than $400 \mathrm{IU} / \mathrm{L}$ as part of the diagnostic criteria of acute $\mathrm{HCV}$ infection [13].

$\mathrm{HCV}$ antibody assays are the most common serologic markers for diagnosis of HCV infection and are usually used as the first line screening test in the community. However, most HCV antibody assays do not correlate well with $\mathrm{HCV}$ viremia and take an average of 6 weeks to 6 months from the onset of infection to become detectable in blood [14].

The term HCV core antigen was first introduced in the clinical practice in 1992. Early methods and their modifications aimed at providing a diagnostic tool of $\mathrm{HCV}$ infection as sensitive and specific as the HCV RNA PCR in cases of acute infection [15] and in follow up of natural or treatment-induced resolution of infection [10] and [16]. Furthermore, it could be useful in monitoring of immunocompromised patients and patients on hemodialysis [17]. Also, the value of HCV core antigen testing was studied in donated blood and plasma to reduce the residual risk of transfusion transmitted infection [18].

In the present study, we adopted the method described by Fabrizi et al. [12] for detecting HCV core antigen and compared it with the gold standard HCV RNA PCR testing in detection of HCV antibody negative HCV infected asymptomtic patients with elevated liver transaminases of unknown etiology.
The present study was carried out at the outpatient clinic of Tropical Medicine Department, Zagazig University where HCV antibody negative patients with elevated liver transaminases of unknown etiology were recruited and the HCV treatment center at Al-Ahrar hospital where HCV antibody positive patients with elevated liver transaminases coming for $\mathrm{HCV}$ treatment were recruited. The study was carried out in the period from April 2015 to February 2017.

Patients were divided into 2 groups; group A which included $55 \mathrm{HCV}$ antibody negative patients with elevated liver transaminases of unknown etiology as the case group and group B which included $55 \mathrm{HCV}$ antibody positive patients with elevated liver transaminases as the control group. HBs antigen positivity, alcoholism, hepatotoxic drug use, ANA positivity, BMI more than 35, sonographically bright fatty liver and hepatocellular carcinoma excluded patients from both groups. Sonographically cirrhotic liver did not exclude patients from either groups.

All patients were subjected to full history taking, thorough clinical examination, routine laboratory investigations in the form of CBC and LFT and pelviabdominal ultrasonogrphy performed by the same operator. HBs antigen and ANA were done for all patients ascertain negativity in all patients. $\mathrm{HCV}$ antibody by a prototype ELISA, HCV core antigen by a prototype ELISA and the gold standard quantitative HCV RNA PCR were done for all patients. HCV antibody testing was repeated after 6 weeks for $\mathrm{HCV}$ infected patients who are initially $\mathrm{HCV}$ antibody negative prior to receiving antiviral treatment. Obtained data were compared using appropriate statistical methods.

In this study, the mean age of HCV antibody negative patients was $41.56 \pm 12.96$ years (range between 19-71 years), 39 of them were males $(70.9 \%)$ and 16 were females $(29.1 \%)$. Regarding $\mathrm{HCV}$ antibody positive patients, the mean age was $42.25 \pm 12.91$ years (range between 19-73 years), 36 of them were males $(65.5 \%)$ and 19 of 
them were females (34.5\%). These findings are in agreement with those of El-Zananty and Way [5] who found that prevalence of chronic HCV infection in Egypt is higher among men than women (12\% and $8 \%$, respectively) and increases with age (reaching $>25 \%$ among persons aged $>50$ years). In this study, body mass index was $25.80 \pm 1.79$ in $\mathrm{HCV}$ antibody negative patients and $25.79 \pm 1.64$ in $\mathrm{HCV}$ antibody positive patients.

There was no statistically significant difference between both groups as regard age, sex and BMI. This reflects that we tried to match patients in both groups as regard age and sex as well as we intentionally execluded patients with BMI more than 35 to eliminate the possibility of fatty liver disease in both groups.

In the present study, there was no statistically significant difference between both groups as regard liver function tests. This reflects that we intentionally selected asymptomatic patients with isolated elevation of liver transaminases in both groups. As regard $\mathrm{CBC}$, there was a statistically significant difference in hemoglobin level and platelet count between both groups. This reflects that we did not execlude cirrhotic patients from either group and reflects that the prevalence of $\mathrm{HCV}$ induced liver cirrhosis is much more common that of cryptogenic cirrhosis. Similar findings were obtained by El Zanaty and Way, 2009 [5] who stated that HCV is the commonest cause of liver disease in Egypt. Similar results of HCV associated thrombocytopenia were obtained by Garcia-Suarez et al. [19] who reported that $\mathrm{HCV}$-associated thrombocytopenia occurs even in the absence of clinically evident liver disease or splenomegaly.

As regard $\mathrm{HCV}$ markers, group A patients initially were all $\mathrm{HCV}$ antibody negative while group $\mathrm{B}$ patients were all $\mathrm{HCV}$ antibody positive. 5 patients in group A turned out to have HCV infection as confirmed by HCV RNA PCR testing. 4 out of these 5 patients were positive for $\mathrm{HCV}$ core antigen. 8 patients in group $B$ turned out to be free of $\mathrm{HCV}$ infection as confirmed by $\mathrm{HCV}$ RNA PCR testing. All of these 8 patients were negative for $\mathrm{HCV}$ core antigen. 44 out the $47 \mathrm{HCV}$ antibody positive $\mathrm{HCV}$ infected patients in group $\mathrm{B}$ were positive for $\mathrm{HCV}$ core antigen while the rest 3 patients were negative for $\mathrm{HCV}$ core antigen.

In this study, there was a statistically highly significant relation between $\mathrm{HCV}$ core antigen positivity and negativity and HCV RNA PCR positivity and negativity respectively in $\mathrm{HCV}$ antibody negative and positive patients $(\mathrm{p}<0.001)$. These results are in agreement with those obtained by Catherine et al. [20] who found that the sensitivity of $\mathrm{HCV}$ core antigen assay was $96.7 \%$ (117 positive HCV core antigen assays out of 121 positive HCV RNA PCR assays) with a highly significant relation between positivity and negativity of $\mathrm{HCV}$ core antigen and HCV RNA PCR in HCV antibody positive patients.

On the other hand, these results are in disagreement with Reddy et al. [21] who reported that the sensitivity of $\mathrm{HCV}$ core antigen assay was $60 \%$ in their study which included 111 chronic renal failure patients on hemodialysis. Difference in results can be explained by the fact that metabolic derangements accompanying CRF may mask the serologic detection of HCV core antigen.

Repeating HCV antibody testing for group A patients after 6 weeks revealed that 3 out of these 55 patients became HCV antibody positive. All of these 3 were $\mathrm{HCV}$ infected from the start as confirmed by HCV RNA PCR testing and all of them were $\mathrm{HCV}$ core antigen positive from the start. This result confirms that $\mathrm{HCV}$ core antigen assay is strongly correlated with HCV RNA PCR assay and can replace it in detection of $\mathrm{HCV}$ infection in the window or pre-seroconversion phase of infection.

These results are in agreement with Lee et al. [22], Piccoli et al. [23], Nubling et al. [24] and Widell et al. [25]. These four prospective and retrospective studies showed that $\mathrm{HCV}$ core assays could detect HCV infection about 40 to 50 days earlier than HCV antibody assays with a an overall sensitivity of $94-97 \%$ and specificity of 99.5-99.9\% in low risk populations.

Also, these results are in agreement with Kobayashi et al. [26] who reported the presence of $\mathrm{HCV}$ antigen in RNA-positive specimens from patients with acute and chronic HCV infection and with Aoyagi et al. [27] who reported the presence of $\mathrm{HCV}$ antigen during the early RNA-positive phase of anti-HCV seroconversion. Their results indicated that HCV core antigen appears substantially earlier than HCV antibody during the early phase of $\mathrm{HCV}$ infection and contemporaneously with HCV RNA in most seroconversion cases.

In conclusion, $\mathrm{HCV}$ core antigen assay is a simple and reliable direct method for detection of $\mathrm{HCV}$ infection among patients with asymptomatic elevation of liver transaminases of unknown 
etiology. Since this assay is based on ELISA technology, it can be easily performed in most laboratories. It would serve as a cheap and rapid direct $\mathrm{HCV}$ detection method in patients during the pre-seroconversion phase when the antibody assays are negative.

Funding: None.

Conflicts of interest: None.

Ethical approval: The protocol of the study was approved by the ethical committee of Faculty of Medicine, Zagazig University. Informed consents were obtained from all patients

\section{REFERENCES}

1- Green R and Flamm S. AGA technical review on the evaluation of liver chemistry tests. Gastroenterology; 2002; 123(4): 1367-84.

2- Blum H. Elevated liver enzymes of unknown etiology (Article in German). Schweiz Rundsch Med Prax, 1994; 83(36): 1011-1013.

3- Orland J, Wright T and Cooper S. Acute hepatitis C. Hepatology; 2001; 33(2): 321-7.

4- Frank C, Mohamed M, Strickland G, Lavanchy D, Arthur R, Magder L, et al. The role of parenteral antischistosomal therapy in the spread of hepatitis C virus in Egypt. Lancet; 2010; 355: 887-891.

5- El-Zanaty F and Way A. Egypt demographic and health survey 2008. Demographic and health surveys; 2009; Cairo, Egypt: Ministry of Health.

6- Thomas D, Factor S, Kelen G, Antonio S, Eric T and Thomas Q. Viral hepatitis in health care personnel at the Johns Hopkins Hospital: the seroprevalence of and risk factors for hepatitis B virus and hepatitis $\mathrm{C}$ virus infection. Arch Intern Med; 2003; 153: 1705-1712.

7- Takahashi K, Okamoto H, Kishimoto S, Munekata E, Tachibana K, akahane Y, et al. Demonstration of a hepatitis $\mathrm{C}$ virus-specific antigen predicted from the putative core gene in the circulation of infected hosts. J Gen Virol; 1992; 73: 667-672.

8- Tanaka T, Lau J, Mizokami M, Orito E, Tanaka E, Kiyosawa K, et al. Simple fluorescent enzyme immunoassay for detection and quantification of hepatitis C viremia. J Hepatol; 1995; 23:742-745.

9- Busch M, Rawal B, Feibig E, Garrett P, Schumacher R, Peddada L, et al. Dynamics of $\mathrm{HCV}$ viremia and seroconversion in transfusionacquired HCV infections (abstract). Transfusion; 1998; 38: 72.

10- Morota K, Fujinami R, Kinukawa H, Machida T, Ohno K, Saegusa H, et al. A new sensitive and automated chemiluminescent microparticle immunoassay for quantitative determination of hepatitis C core antigen.J Virol Methods; 2009: 157: 8-14.

11- Ross R, Viazov S, Salloum S, Hilgard P, Gerken G and Roggendorf $M$. Analytical performance characteristics and clinical utility of a novel assay for total hepatitis $\mathrm{C}$ virus core antigen quantification. J Clin Microbiol; 2010; 48: 11611168.

12- Fabrizi F, Lunghi G, Aucella F, Mangano S, Francesco B, Sergio B. et al. HCV core antigen quantification for diagnosis of HCV. Journal of clinical Microbiology; 2005; 43(1): 414-420.

13- Mostafa A, Taylor S, El-Daly M, El-Hoseiny M, Bakr I, Arafa N, et al. Is the hepatitis $\mathrm{C}$ virus epidemic over in Egypt? Incidence and risk factors of new hepatitis $\mathrm{C}$ virus infections. Liver Int; 2010; 30 (4): 560-566.

14- Richter S. Laboratory assays for diagnosis and management of hepatitis $\mathrm{C}$ virus infection. J Clin Microbiol; 2002; 40(12): 4407-12.

15- Petersona J, Green G, Iida K, Caldwell B, Kerrison P, Bernich S, et al. Detection of hepatitis $\mathrm{C}$ core antigen in the antibody negative 'window' phase of hepatitis C infection. Vox Sang; 2000: 78: 80-85.

16- Mario M. Monitoring response to antiviral treatment by serum hepatitis $\mathrm{C}$ virus core antigen: too early to take shortcuts?. Journal of Hepatology; 2004: 40: 536-538.

17- Medhi S, Potukuchi S, Polipalli S, Swargiary S, Deka P, Chaudhary A, et al. Diagnostic utility of hepatitis $\mathrm{C}$ virus core antigen in hemodialysis patients. Clin. Biochem.; 2008; 41:447-452.

18- Agha S, Tanaka Y, Saudy N, Kurbanov F, AboZeid M, El-Malky M, et al. Reliability of hepatitis $\mathrm{C}$ virus core antigen assay for detection of viraemia in HCV genotypes 1,2,3 and 4 infected blood donors: a collaborative study between Japan, Egypt and Uzbekistan. J Med Virol; 2004; 73: 216-22.

19- Garcia-Suarez J, Burgaleta C, Hernanz N, Albarran F, Tobaruela P and Alvarez-Mon M. $\mathrm{HCV}$-associated thrombocytopenia: clinical characteristics and platelet response after recombinant a 2b-interferon therapy. British Journal of Haematology; 2000; 110, 98-103.

20- Catherine G, Catherine T, Jean T, Nicole M, Alain $G$ and Frederic D. Usefulness of the Hepatitis C Virus Core Antigen Assay for Screening of a Population Undergoing Routine Medical Checkup. Journal of Clinical Microbiology; 2005; 43(4): 1722-26.

21- Reddy A, Murthy K and Lakshmi V. Prevalence of $\mathrm{HCV}$ infection in patients on hemodialysis: 
Survey by antibody and core antigen detection. Indian J Med Microbiol; 2006; 23: 106-10.

22- Lee SR, Peterson J, Niven C, Bahl C, Page E, DeLeys R, et al. Efficacy of a hepatitis $\mathrm{C}$ virus core antigen enzyme-linked immunosorbent assay for the identification of 'window-phase' blood donations. Vox Sang; 2001; 80: 19-23.

23- Piccoli P, Franchini M, Gandini G, Antonello O, Olzer D, Turrini A, et al. HCV core antigen assay. Transfusion; 2001; 41: 1172.

24- Nubling CM, Unger G, Chudy M, Raia S and Löwer J. Sensitivity of HCV core antigen and HCV RNA detection in the early infection phase. Transfusion; 2002; 42: 1037-45.
25- Widell A, Molnegren V, Pieksma F, Calmann M, Peterson $\mathrm{J}$ and Lee S. Detection of hepatitis C core antigen in serum or plasma as a marker of hepatitis $\mathrm{C}$ viraemia in the serological windowphase. Transfus Med; 2002; 12: 107-13.

26- Kobayashi M, Tanaka E, Matsumoto A, Yoshizawa K, Imai $\mathrm{H}$, Sodeyama $\mathrm{T}$, et al. Clinical application of hepatitis $\mathrm{C}$ virus core protein in early diagnosis of acute hepatitis C. $J$ Gastroenterol; 1998; 33: 508-11.

27- Aoyagi K, Ohue C, Iida K, Kimura T, Tanaka E, Kiyosawa $\mathrm{K}$ et al. Development of a simple and highly sensitive enzyme immunoassay for hepatitis C virus core antigen. J Clin Microbiol; 1999; 37: 1802-8. 